\title{
MUJERES Y HOMBRES EN LAS ÉLITES POLÍTICAS ESPAÑOLAS: ¿DIFERENCIAS O SIMILITUDES?
}

\section{Edurne Uriarte y Cristina Ruiz}

\begin{abstract}
RESUMEN
Este artículo analiza las diferencias de género en la élite política española a partir de los datos obtenidos en una investigación realizada por las autoras en 1997 sobre los diputados y diputadas de la actual legislatura. El artículo parte de un análisis introductorio sobre los factores que explican el importante porcentaje, en términos comparativos, de mujeres que han llegado a la élite política en España y sobre los factores que explican, a su vez, que las diferencias de número entre hombres y mujeres se mantengan. Fundamentalmente, el artículo pretende responder a tres interrogantes básicos: 1) ¿existen diferencias entre los hombres y mujeres de la élite política?; 2) ¿cuáles son las causas que explican la menor presencia de mujeres en posiciones de poder, y 3) ¿podemos hablar de diferencias en la forma en que hombres y mujeres ejercen el liderazgo?
\end{abstract}

\section{INTRODUCCIÓN: EL PROGRESIVO AUMENTO DE MUJERES EN LAS ÉLITES POLÍTICAS ESPAÑOLAS}

Uno de los rasgos característicos de las élites políticas en todos los países del mundo es la importante diferencia en número de hombres y mujeres. Con contadas excepciones, como Suecia y Noruega, la presencia de mujeres en

${ }^{1}$ Los datos sobre la élite política española que aparecen en este artículo corresponden a la investigación La influencia del género en el reclutamiento de la élite política, subvencionada por el Instituto de la Mujer y dirigida por Edurne URIARTE.

\section{Reis}


todos los niveles del poder político, gobiernos, parlamentos y partidos políticos, se aleja todavía notablemente del 50 por 100 . Ahora bien, esta presencia aún minoritaria de las mujeres se acompaña en los países desarrollados con un segundo rasgo no menos importante, el aumento constante del número de mujeres en todos los niveles de poder en los últimos años.

España constituye un país representativo de esta doble característica, es decir, España tiene una élite política con una importante diferencia en número entre hombres y mujeres, pero, al mismo tiempo, ha asistido en los últimos años a un constante aumento del número de mujeres en las posiciones de poder, básicamente en el último decenio. Del 6 por 100 de mujeres en el Congreso de las cuatro primeras legislaturas se pasó en 1989 al 14,6 y al 15,7 por 100 en 1993, y en 1996 se saltó al 24,3 por 100 actual. La evolución en el terreno del poder ejecutivo ha sido semejante y se refleja en la actualidad en el 26,6 por 100 de mujeres que componen el gobierno. Estos porcentajes han situado a España entre los primeros países europeos, y, por lo tanto, del mundo, en número de mujeres en la Cámara Baja y la han puesto por delante de países de larga tradición democrática y económicamente tan desarrollados como Gran Bretaña, Francia o Luxemburgo, y a nivel semejante de otros países como Alemania y Austria.

España se ha situado, por lo tanto, entre los primeros países en el ritmo de equiparación de mujeres en términos de poder político. Pero, al mismo tiempo, y al igual que prácticamente todos los países desarrollados, España sigue manteniendo unas importantes diferencias de género entre las élites políticas. Esta realidad nos plantea dos preguntas de interés que centrarán nuestro análisis en las siguientes páginas. En primer lugar, ¿por qué un país mediterráneo, católico y de breve tradición democrática como España presenta una presencia mayor de mujeres entre su élite política que otros países más desarrollados y de rasgos culturales aparentemente más abiertos al concepto de igualdad femenina? En segundo lugar, ¿`ómo es la élite política española? y, básicamente, ¿existen diferencias entre los hombres y mujeres de la élite política? Esta segunda cuestión, que es la más compleja, nos remite a su vez a numerosas interrogantes, de las que nos proponemos responder a tres: 1) las similitudes y diferencias en términos de caracterización; 2) las características del reclutamiento, y 3) la diferenciación en términos de liderazgo.

Para responder a la primera cuestión, nos referiremos a algunos rasgos de la cultura política de los españoles, de la participación política, de la religiosidad, y también nos referiremos a aspectos del sistema de partidos, del sistema electoral y del tipo de reclutamiento de las élites políticas. Un análisis de estos datos en perspectiva comparada nos permitirá avanzar algunas respuestas a la primera de las cuestiones.

Para responder a la segunda cuestión, es decir, la referente a la caracterización de la élite política española y a las diferencias y similitudes de las mujeres y hombres de la élite política española, nos basaremos en una investigación que realizamos sobre los diputados y diputadas del Congreso español de la sép- 
tima legislatura (1996-2000), En el marco de esta investigación, cuyo trabajo de campo se realizó en 1997, se enviaron cuestionarios a todos los miembros del Congreso y se obtuvieron 212 respuestas, es decir, se obtuvo un nivel de respuesta del 60,9 por 100 del total de los miembros de la Cámara de Diputados. El cuestionario se componía de preguntas cerradas y abiertas, si bien en las siguientes páginas nos referiremos únicamente a los datos obtenidos a través de algunas de las preguntas cerradas.

Es importante señalar que los datos sobre los diputados españoles se utilizarán en las siguientes páginas para hacer generalizaciones sobre la élite política española actual. La consideración de la élite parlamentaria como representativa del conjunto de la élite política ha sido ampliamente fundamentada en numerosos estudios sobre élites políticas realizados en la ciencia política. En otro lugar nos hemos referido a esos estudios y a las razones que justifican la elección de la élite parlamentaria como base empírica para el estudio de las élites políticas ${ }^{2}$. Cabe sintetizar brevemente esas razones de la siguiente forma: 1) desde el llamado análisis posicional, el Parlamento es una de las instituciones esenciales desde las que se ejerce el poder político; 2) además, las posiciones de poder del Parlamento están fuertemente interconectadas con los otros dos centros esenciales del poder político, es decir, con el ejecutivo y las cúpulas de los partidos políticos, de dos formas: a) una buena parte de esas cúpulas está, a su vez, en el Parlamento, y b) el Parlamento constituye un importante lugar de selección de los miembros del ejecutivo, y 3) por último, el análisis de la élite parlamentaria ofrece muchas menos complicaciones al investigador para realizar el trabajo de campo y para tener acceso a los datos.

\section{LOS FACTORES DEL ASCENSO FEMENINO, LOS FACTORES DE LA PERSISTENCIA DE DIFERENCIAS DE GÉNERO}

Hace ya bastantes años, Ronald Inglehart hacía una clasificación de países en relación a la distancia de género o gender gap, que este autor medía en porcentajes de hombres y mujeres que discutían sobre política. Inglehart mostraba que España era el sexto país entre 19 donde la distancia de género era mayor. Le acompañaban dentro de los primeros puestos en distancia de género Italia, Portugal, Grecia, Japón e Irlanda ${ }^{3}$. La distancia de género de la que hablaba Ronald Inglehart se refería a la cultura política y no a las élites políticas. Sin embargo, y dada la influencia de la cultura política en la determinación de muchos de los rasgos del sistema político, resulta hasta cierto punto llamativo que, en contra de lo que hacían suponer los datos de Ronald Inglehart, España

2 E. URIARTe, «El análisis de las élites políticas en las democracias», Revista de Estudios Politicos, núm. 97, julio-septiembre 1997.

3 R. INGLEHART, El cambio cultural en las sociedades industriales avanzadas, CIS, Madrid, 1991 , pp. 390 y 391. 
se haya situado entre los primeros países de Europa en el apartado de la presencia de mujeres entre las élites políticas.

Tal como podemos ver en la tabla 1 , el porcentaje de mujeres entre los diputados de la Cámara Baja española es el séptimo mayor de los países de la Unión Europea y, además, es notablemente superior a los países que quedan por debajo de España en esta clasificación. La fortaleza de la presencia femenina entre la élite política española se confirma cuando atendemos a los datos relativos a los gobiernos. En efecto, el porcentaje de mujeres en el gobierno español no sólo supera el 25 por 100 (es de un 26,6 por 100), sino que sitúa a España en el sexto lugar de la Unión Europea en términos de presencia de mujeres en los ejecutivos, tan sólo por detrás de los países nórdicos, Austria y Holanda.

Si atendemos a la distribución de países en la clasificación según importancia de la presencia de mujeres en las élites políticas y si pretendemos explicar, además, las razones por las cuales España ocupa una posición relativamente privilegiada en esa clasificación, observamos que los factores que explican la importancia y el ritmo de la llegada de mujeres al poder político son complejos.

\section{TABLA 1}

Mujeres en las Cámaras Bajas de los paises de la Unión Europea

\begin{tabular}{|c|c|c|}
\hline Estado & Fecha elecciones & Porcentaje mujeres \\
\hline Suecia & 1994 & 40,4 \\
\hline 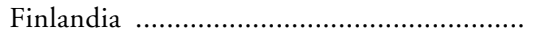 & 1995 & 33,5 \\
\hline 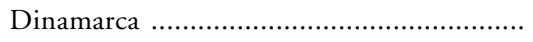 & 1994 & 33 \\
\hline . & $1994-95$ & 31,3 \\
\hline 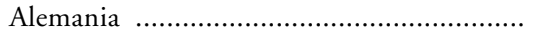 & 1994 & 26,3 \\
\hline 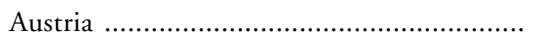 & 1995 & 25,6 \\
\hline 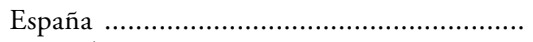 & 1996 & 24,3 \\
\hline Luxemburgo . ................................................ & 1994 & 16,7 \\
\hline Italia & 1994 & 13,9 \\
\hline 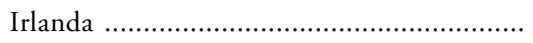 & 1992 & 13,3 \\
\hline 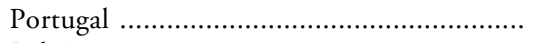 & 1995 & 12,2 \\
\hline 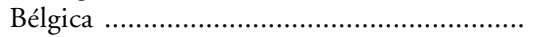 & 1995 & 11,3 \\
\hline 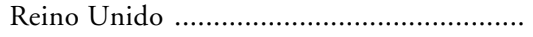 & 1992 & 9,2 \\
\hline 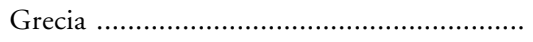 & 1993 & 5,7 \\
\hline
\end{tabular}

FueNte: Edurne Uriarte y Arantxa Elizondo (coords.), Mujeres en politica, Ariel, 1997, p. 338.

En primer lugar, las posiciones de algunos de los países más pobres de Europa, como Grecia y Portugal, en los puestos de cola muestran que el desarrollo económico es uno de los factores que explica la mayor o menor incorporación de mujeres a los núcleos de poder. El desarrollo económico está relacio- 
nado con un mayor desarrollo del sistema educativo y, por lo tanto, con la incorporación de mujeres a ese sistema educativo, y también con el desarrollo de determinados valores favorecedores de la participación de las mujeres en todos los niveles de la vida pública. Ahora bien, las posiciones de Francia y, sobre todo, del Reino Unido en los mismos lugares de cola muestran que debemos buscar también otros factores para explicar los diferentes ritmos de incorporación de mujeres a las élites políticas.

Frecuentemente se ha aludido al catolicismo como factor explicativo de los ritmos lentos de incorporación de mujeres a las élites políticas y de las distancias de género importantes en términos de cultura política y de participación $\mathrm{n}^{4}$. Ahora bien, la posición de dos países mayoritariamente católicos como España y Austria entre los países con más presencia de mujeres en las élites políticas, y la posición de dos países mayoritariamente protestantes como el Reino Unido y Estados Unidos 5 entre los países con menor presencia femenina en la cima de la política, muestran que también esa explicación es totalmente insuficiente.

En tercer lugar, se ha hablado también del sistema de partidos y, en concreto, de la importancia de la presencia de partidos de izquierda fuertes, laboristas, socialdemócratas, comunistas y verdes. Los partidos de izquierda han asumido de forma mucho más importante el discurso feminista que los partidos conservadores, básicamente porque el discurso de la igualdad del feminismo encaja en las ideologías de izquierdas pero de forma mucho más complicada en las ideologías de derechas ${ }^{6}$. El caso español es un ejemplo de la importancia de la existencia de partidos de izquierda fuertes para el aumento de la presencia de mujeres en las élites. Y es que el salto de la presencia de mujeres en el Parlamento que se produce en 1989 con respecto a las legislaturas anteriores está relacionado de forma significativa con la aplicación de las cuotas en 1988 en los dos principales partidos de izquierda en España, el PSOE y el PCE. En los años y legislaturas siguientes, la consolidación y la ampliación de la cuota en estos partidos no sólo fomenta el aumento de la presencia de mujeres entre las élites, sino que también provoca un efecto de respuesta en los partidos de centro y conservadores que no lleva al establecimiento de una cuota en estos partidos pero sí fomenta la presencia de mujeres en sus ámbitos de decisión.

${ }^{4}$ Véase, por ejemplo, T. Jelen, S. Thomas y C. Wilcox, «The Gender Gap in Comparative Perspective», European Journal of Political Research, vol. 25, núm. 2, 1994. Es bien conocido entre los politólogos, por otra parte, el enorme interés de los investigadores anglosajones en torno a los supuestos efectos negativos del catolicismo en el proceso de equiparación de sexos en los países católicos europeos. Si bien es preciso profundizar en el análisis de esta cuestión, cabe plantear la hipótesis del error de partida sobre el que se sustentaría el interés de estos investigadores, que es la suposición de una influencia mucho mayor de la realmente existente de los valores católicos en el conjunto de valores sociales, morales y políticos en la sociedad española.

5 El porcentaje de mujeres en el Congreso norteamericano tras las elecciones de 1994 es del 10,8 por 100 .

${ }^{6}$ Norberto Bobbio hace un excelente análisis de esta cuestión en N. BobBIO, Derecha e izquierda, Taurus, Madrid, 1995. 
En cuarto lugar, otro factor que se ha apuntado como influyente en la determinación de la fuerza de la incorporación de las mujeres a las élites políticas es el del grado de centralización en la selección de candidatos. Hay autores que han señalado que el reclutamiento centralizado es favorable a las mujeres dado que en este tipo de reclutamiento el peso básico de la decisión está en los sectores de mayor educación formal del partido y, por lo tanto, posiblemente más abiertos a la incorporación de las mujeres, frente a las actitudes más restrictivas que pueden encontrarse en los reclutamientos más dirigidos desde ámbitos locales ${ }^{7}$. Si bien esta hipótesis no está lo suficientemente contrastada, lo cierto es que este factor parece tener cierta relevancia en España, donde el importante número de mujeres en las élites ha podido ser estimulado por el hecho de que España, junto a Luxemburgo y Holanda, constituye uno de los países europeos donde los líderes del poder central juegan un papel más importante en los procesos de reclutamiento ${ }^{8}$.

El sistema electoral, por último, es también un factor señalado por algunos analistas. Pippa Norris ha estudiado la relación de la presencia de mujeres en las Cámaras Bajas de 44 países con sus sistemas electorales y ha concluido que la media de mujeres parlamentarias es de un 8,3 por 100 en los sistemas mayoritarios, de un 12,9 por 100 en los sistemas semiproporcionales y de un 17,3 por 100 en los sistemas proporcionales ${ }^{9}$. Es decir, de estos datos podemos deducir también que el sistema electoral proporcional es otro de los factores que han influido en España en el importante crecimiento de la presencia de mujeres en las élites políticas.

Por lo tanto, un país de desarrollo económico medio en el conjunto europeo, católico y de una tradición democrática todavía breve presenta, sin embargo, una notable presencia de mujeres entre sus élites políticas. ¿Cómo podemos explicar esta importancia de la incorporación de las mujeres españolas a posiciones de poder político? A falta de una mayor profundización en el análisis comparado de esta cuestión, podemos destacar tres factores explicativos claros que se han señalado en el análisis como favorecedores de este proceso: 1) la existencia de un gran partido socialdemócrata, el PSOE, que, además, ha permanecido catorce años en el poder y en un período esencial para el proceso de incorporación de mujeres; 2) el reclutamiento político centralizado, y 3) la existencia de un sistema electoral proporcional.

Ahora bien, tenemos que responder en segundo lugar a la cuestión que se planteaba en la segunda parte del título de este epígrafe, es decir, la de cuáles son los factores que explican a su vez que las diferencias en términos de presencia en las élites de hombres y mujeres continúen siendo importantes en España. Son conocidas sobradamente las influencias, por otra parte comunes a

7 Véase V. Randall, Women and Politics, Macmillan, Londres, 1987.

8 Véase P. Norris, "Comparing Passages to Power", dentro de P. Norris (ed.), Passages to Power, Cambridge University Press, 1997.

9 P. NORRIS, «Procesos de reclutamiento legislativo: una perspectiva comparada", dentro de E. URIARTE y A. Elizondo, op. cit., p. 166. 
todos los países, de un proceso de socialización diferenciado, de las diferencias en grado de educación formal y de la reciente entrada de las mujeres en el mundo del trabajo remunerado y, por lo tanto, en la posibilidad de plena participación en la vida pública ${ }^{10}$.

Los factores señalados determinan en buena medida una distancia de género aún importante en términos de cultura política y participación política que tienen notable importancia para comprender las diferencias en el terreno de las élites políticas. Varios años después del análisis de Inglehart que señalábamos más arriba, los datos muestran que la distancia de género en España sigue siendo notable en términos de cultura y participación políticas. En 1994 había un 31 por 100 de hombres muy o bastante interesados en política, frente a un 20 por 100 de las mujeres. Además, un 42 por 100 de los hombres se consideraba muy o bastante al corriente de la política, frente a un 26 por 100 de las mujeres. Y mientras que casi un 63 por 100 de los hombres leía diarios, el porcentaje de mujeres se reducía al 37,1 por $100^{11}$.

La participación electoral sí se ha equiparado notablemente en los años noventa. No sólo las diferencias en términos de abstención son muy pequeñas, sino que las tendencias de voto a la izquierda y la derecha se han nivelado en términos de género. Ahora bien, la afiliación de las mujeres a los partidos políticos sigue siendo notablemente menor ${ }^{12}$, y lo mismo ocurre con la participación no convencional. Contrariamente a lo que han sostenido algunas teorías, no podemos hablar de una participación política diferente de las mujeres, no podemos hablar de otra noción de política. Las mujeres no sólo no han desarrollado ningún espacio nuevo que permita una reconsideración del concepto de política, sino que, además, también participan menos en aquellos espacios más alejados de la participación convencional y de la política tradicional.

Los datos sobre participación no convencional en España muestran que también en este terreno el porcentaje de mujeres es significativamente inferior al de hombres. Además, el análisis de los datos relativos a pertenencia a organizaciones no políticas o no directamente políticas muestra que los hombres pertenecen en mayores porcentajes a organizaciones culturales, deportivas, de vecinos, de derechos humanos, ecologistas, de consumidores y profesionales, y que las mujeres tan sólo superan en número a los hombres en organizaciones de mujeres y en organizaciones benéficas ${ }^{13}$.

${ }^{10}$ Véase, por ejemplo, E. URIARTE, «Pautas de cultura política y participación en España», dentro de E. Uriarte y A. Elizondo (eds.), Mujeres en politica, Ariel, Barcelona, 1997.

11 Son datos del CIS, 1994.

12 Anders Widfeldt ha mostrado que la media de afiliación femenina de nuestro país es de un 24 por 100, lo cual nos sitúa no sólo a notable distancia de la afiliación masculina, sino también en penúltimo lugar en porcentajes de afiliación femenina a partidos políticos, tan sólo por delante de Luxemburgo, que registra el porcentaje más bajo; en A. WIDFELDT, «Party membership and Party Representativeness», en H. D. Klingemann y D. Fuchs (eds.), Citizens and the State, Oxford University Press, Oxford, 1995, p. 148.

13 Son datos del CIS, 1989. 
Por lo tanto, todavía persisten en España rasgos culturales diferenciados de hombres y mujeres en su relación con el sistema político. Las mujeres conocen menos y se interesan menos por el sistema político, participan menos en las organizaciones esenciales de ese sistema político y participan menos también en otros niveles sociales y culturales de importante influencia en lo político, y estos déficits de participación y de cultura política explican una buena parte de las causas de la debilidad de la presencia femenina en los centros de poder político.

\section{LAS CARACTERÍSTICAS DE LAS ÉLITES POLÍTICAS}

Un análisis de las características básicas de los hombres y mujeres de la élite política española revela básicamente similitudes y escasas diferencias, relacionadas estas últimas en buena medida con el más tardío acceso de las mujeres a posiciones de élite. La élite política española muestra en su conjunto los rasgos centrales que han sido observados en los trabajos realizados sobre élites políticas de diversos países ${ }^{14}$. En términos de orígenes y formación, también en el caso español, predominan en la élite política los orígenes de clase acomodados, los orígenes urbanos y la alta formación ${ }^{15}$.

Tanto hombres como mujeres de la élite política tienen en común orígenes de clase acomodados, notablemente más acomodados que los del conjunto de la población. No se registran diferencias significativas entre hombres y mujeres y prevalece el dato general de la importancia de los orígenes de clase media-alta y alta $(28,6$ por 100$)$ y de la clase media-media $(36,7 \text { por } 100)^{16}$. Si bien partíamos de la hipótesis de unos orígenes de clase más altos en las mujeres que en los hombres, a partir de la teoría de que esa ventaja de origen podía ser necesaria para que las mujeres pudieran superar otros obstáculos en su camino hacia la élite política, el caso español no ha permitido corroborar esta hipótesis ${ }^{17}$.

La élite política también se caracteriza por la importancia de la formación universitaria. Los porcentajes de diputados con formación universitaria supe-

14 Para un análisis más pormenorizado de estas investigaciones y de estos datos, véase E. URIARTE, «El análisis de las élites políticas en las democracias», op. cit.

15 Tanto estos datos como todos los que se van a citar en las siguientes páginas en torno a la élite política española y las tablas que se van a presentar corresponen, tal como se ha indicado más arriba, a la investigación realizada por las autoras sobre los diputados de la séptima legislatura.

${ }^{16}$ Se apuntan los porcentajes que corresponden a la propia autoubicación de los entrevistados. Ahora bien, la comparación de esta autoubicación con el dato de profesión de los padres sí permite señalar que se registra una tendencia entre los diputados a una autoubicación algo más baja que la correspondiente a la profesión de los padres.

${ }_{17}$ La diferencia de orígenes de clase entre mujeres y hombres de las élites políticas sí ha podido ser constatada en el caso holandés, donde un análisis del background de los diputados holandeses entre 1918 y 1986 revela que un 79 por 100 de las mujeres parlamentarias procede de las clases más acomodadas, frente a un 47 por 100 de los hombres; en M. LEIJENNAAR y K. Niemöller, «The Netherlands», dentro de P. Norris, op. cit., p. 126. 
ran ampliamente el 50 por 100 en la mayoría de los países. España se caracteriza por un porcentaje especialmente alto de formación universitaria entre su élite política. Tal como podemos ver en la tabla 2, el porcentaje del conjunto de diputados que tienen al menos una licenciatura universitaria, y en algunos casos también un postgrado o doctorado, es del 75 por 100, es decir, un porcentaje muy similar al del 78 por 100 que señala Pippa Norris con datos de la anterior legislatura, y que situaban a España como el país con mayor porcentaje de diputados con formación universitaria en una comparación de diez países europeos $^{18}$.

\section{TABLA 2}

Nivel de estudios de los diputados (\%)

\begin{tabular}{|c|c|c|c|}
\hline & Hombre & Mujer & Total \\
\hline 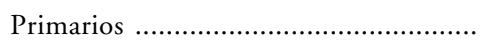 & 1,2 & 2,0 & 1,4 \\
\hline Secundarios & 7,4 & 10,2 & 8,0 \\
\hline Escuela Universitaria ............................ & 13,5 & 22,4 & 15,6 \\
\hline 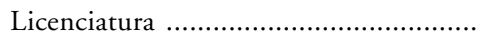 & 58,3 & 51,0 & 56,6 \\
\hline Postgrado/Doctorado ............................ & 19,6 & 14,3 & 18,4 \\
\hline
\end{tabular}

FUENTE: Elaboración propia.

En la misma comparación que establecía Pippa Norris, y aquí entramos en el terreno de las diferencias entre hombres y mujeres, se observaba que la formación universitaria de las mujeres parlamentarias era algo menor. Un 50 por 100 de las parlamentarias de los diez países analizados tenía titulación universitaria, frente a un 63 por 100 de los hombres ${ }^{19}$. El análisis de los datos sobre los diputados españoles de la actual legislatura confirma esta diferencia y muestra que hay un 64,3 por 100 de licenciadas y doctoras, frente a un 77,9 por 100 de licenciados y doctores (tabla 2).

También se observan algunas diferencias en el tipo de formación y en la profesión de origen de diputados y diputadas españoles. A pesar de que se ha registrado un descenso de su peso en los últimos años, los estudios de Derecho siguen siendo los más frecuentes entre la élite política española, al igual que ocurre con las élites de otros países ${ }^{20}$. Ahora bien, los estudios de Derecho son comparativamente más numerosos entre los diputados que entre las diputadas, y es la licenciatura en Filosofía y Letras la más frecuente entre estas últimas. Tenemos que tener en cuenta que estamos hablando de parlamentarios que en

18 P. NORRIS, op. cit.

19 P. NORRIS, op. cit.

${ }^{20}$ Véase E. URIARTE, op. cit. 
su inmensa mayoría han superado los cuarenta años y que, por lo tanto, se han formado en una época en que aún se registraban importantes diferencias no sólo en el acceso de hombres y mujeres a la universidad, sino también en el tipo de estudios elegidos.

En correspondencia con lo observado en torno a la formación, también la profesión de abogado continúa siendo la más importante profesión de origen entre el conjunto de diputados, seguida de la de funcionario y, en tercer lugar, de la de profesor de universidad. Ahora bien, se observan algunas diferencias entre hombres y mujeres, ya que mientras es más importante la abogacía entre los hombres (un 17,8 por 100, frente a un 8,2 por 100 de las mujeres), las profesiones de profesor de universidad y funcionario son algo más numerosas entre las mujeres.

La caracterización básica de los hombres y mujeres de la élite política española muestra, por último, que el porcentaje de mujeres es algo más elevado entre los diputados que superan los cuarenta años y que, también contrariamente a nuestra hipótesis inicial de que las mujeres diputadas serían más jóvenes que sus compañeros diputados, los datos muestran que esto no es así (tabla 3). La hipótesis de la mayor juventud de las mujeres de la élite política se basaba en el dato de la entrada más tardía de las mujeres en las posiciones de poder, dato que nos llevaba a suponer que eran las mujeres más jóvenes las que accedían básicamente a esa carrera política. Pero, tal como nos muestran los datos sobre la edad y otros datos sobre la carrera política que veremos a continuación, hemos podido constatar que esto no es así, y que la edad de las mujeres es algo mayor que la de los hombres.

\section{TABLA 3}

Edad de los diputados (\%)

\begin{tabular}{|c|c|c|c|}
\hline & Hombre & Mujer & Total \\
\hline 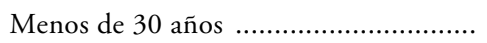 & 1,2 & & 0,9 \\
\hline 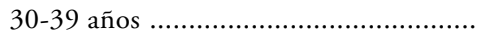 & 13,5 & 4,1 & 11,3 \\
\hline 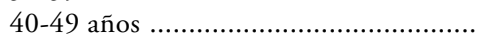 & 33,7 & 40,8 & 35,4 \\
\hline 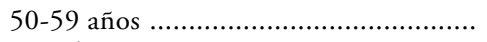 & 36,8 & 46,9 & 39,2 \\
\hline Más de 60 años ..................................... & 12,9 & 8,2 & 11,8 \\
\hline NC & 1,8 & & 1,4 \\
\hline TOTAL ......... & 76,9 & 23,1 & 100 \\
\hline
\end{tabular}

FUENTE: Elaboración propia.

El análisis de los datos relativos a las carrreras políticas de los hombres y mujeres de la élite política permite corroborar básicamente la tesis sustentada por Pippa Norris en su análisis comparativo de varios países de que no se 
observan diferencias significativas en la carrera política de hombres y mujeres ${ }^{21}$. Las diferencias que se observan se fundamentan básicamente en la más tardía incorporación de las mujeres y no tanto en la existencia de unas trayectorias diferenciadas según género.

En correspondencia con los ritmos de incorporación de las mujeres a la élite política, el porcentaje de diputadas para las cuales la actual legislatura es su primera legislatura es notablemente superior al de los hombres. Tal como podemos observar en la tabla 4, la legislatura 1996-2000 es la primera para el 61,2 por 100 de las mujeres, frente al 38,0 por 100 de los hombres.

TABLA 4

Primera legislatura según género (\%)

\begin{tabular}{|c|c|c|}
\hline & Hombres & Mujeres \\
\hline Sí & 38 & 61,2 \\
\hline No & 60,7 & 38,8 \\
\hline NC & 1,2 & - \\
\hline
\end{tabular}

FUENTE: Elaboración propia.

Ahora bien, cuando observamos otros dos datos relevantes de la carrera política de hombres y mujeres, los relativos al tiempo de militancia en sus partidos políticos y a la pertenencia a los comités ejecutivos, comprobamos que los rasgos principales son comunes a ambos sexos. En primer lugar, y en relación al tiempo de militancia en sus partidos políticos, la característica principal es la del alto período de militancia de la élite política. Podemos observar en la tabla 5 que un 67,8 por 100 de los diputados está afiliado desde hace al menos diez años, y que la comparación entre diputados y diputadas no arroja diferencias significativas respecto a esta cuestión.

A pesar de que las mujeres se han incorporado más recientemente a las posiciones de élite, también ellas han seguido carreras políticas semejantes. $\mathrm{Y}$ es bien sabido que, en las llamadas democracias de partido, son los partidos políticos los centros esenciales de reclutamiento de las élites políticas. Esto significa que la militancia y la dedicación al partido político resultan requisitos de enorme, si no trascendental, importancia para llegar a posiciones de élite política $^{22}$.

${ }^{21}$ P. NORRIS, op. cit.

${ }^{22}$ Ian McAllister señala en relación a Australia que el tiempo medio de militancia en sus partidos políticos de los candidatos al Parlamento australiano era de 12,3 años, mientras que el tiempo medio de militancia de los parlamentarios era algo mayor de 22 años; en I. MCALLister, "Australia», dentro de P. NORRIS, op. cit. 


\section{TABLA 5}

Tiempo de militancia de los diputados (\%)

\begin{tabular}{|c|c|c|c|}
\hline Años militando & Hombre & Mujer & Total \\
\hline Menos de 2 años & 1,8 & 4,1 & 2,4 \\
\hline 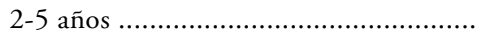 & 8,0 & 12,2 & 9,0 \\
\hline 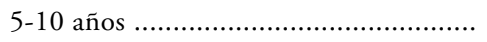 & 16,6 & 14,3 & 16,0 \\
\hline 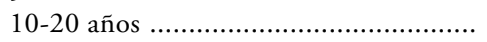 & 39,3 & 51 & 42,0 \\
\hline Más de 20 años ................................... & 31,3 & 16,3 & 27,8 \\
\hline NC & 3,1 & 2,0 & 2,8 \\
\hline 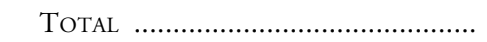 & 76,9 & 23,1 & 100 \\
\hline
\end{tabular}

FUENTE: Elaboración propia.

Junto a una larga dedicación al partido, la pertenencia a los núcleos de poder de la organización se revela también como requisito de gran importancia para acceder a posiciones de élite. Casi el 70 por 100 de diputados pertenecen a algún comité ejecutivo de sus respectivos partidos (tabla 6). Además, se observa que la pertenencia de mujeres a los órganos máximos de poder de los partidos políticos es algo menor que la de los hombres. Esta diferencia sugiere la hipótesis de que la introducción de las cuotas y el fomento desde la dirección de los partidos políticos de la incorporación de las mujeres han podido estimular la cooptación por parte de los líderes políticos de mujeres de otros ámbitos como la cultura o la universidad, es decir, de mujeres que no han seguido la trayectoria tradicional de alta dedicación al partido político antes de ser seleccionada para acceder al Parlamento.

TABLA 6

Pertenencia de los diputados a comités ejecutivos (\%)

\begin{tabular}{|c|c|c|c|}
\hline & Hombre & Mujer & Total \\
\hline 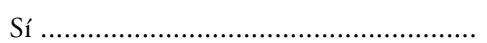 & 72,4 & 61,2 & 69,8 \\
\hline No & 27 & 34,7 & 28,8 \\
\hline NC & 0,6 & 4,1 & 1,4 \\
\hline TOTAL & 76,9 & 23,1 & 100 \\
\hline
\end{tabular}

FUENTE: Elaboración propia. 
Por otra parte, el análisis de los diferentes comités ejecutivos de pertenencia muestra que, entre los diputados españoles que pertenecen a comités ejecutivos, pertenecen a comités ejecutivos provinciales en un 44,3 por 100 , a comités ejecutivos regionales en un 16,5 por 100 y a comités ejecutivos nacionales en un 7,5 por $100^{23}$.

El análisis de las carreras políticas de las élites políticas muestra, por último, un alto nivel de pertenencia a otro tipo de organizaciones con influencia importante en la política, básicamente sindicatos, grupos de interés, movimientos sociales y organizaciones culturales. En primer lugar, en relación a los sindicatos, no se aprecian diferencias significativas entre hombres y mujeres en los niveles de pertenencia. Las diferencias principales se producen en términos de partidos políticos. Al igual que ocurre en otros países, la pertenencia a sindicatos es muy importante en los partidos de izquierda, PSOE e IU (tabla 7), y poco importante en los partidos de derecha. Los sindicatos obreros, básicamente UGT y CC.OO. en España, no sólo han estado muy ligados a los partidos de izquierda hasta muy recientemente, sino que, además, los sindicatos han constituido una de las vías de acceso a la élite política ${ }^{24}$.

\section{TABLA 7}

Pertenencia a sindicatos según género y partidos políticos (\%)

\begin{tabular}{|c|c|c|c|c|c|c|}
\hline & \multicolumn{2}{|c|}{$P P$} & \multicolumn{2}{|c|}{ PSOE } & \multicolumn{2}{|c|}{$I U$} \\
\hline & Hombre & Mujer & Hombre & Mujer & Hombre & Mujer \\
\hline 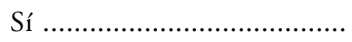 & 12,3 & 10,0 & 69,1 & 67,9 & 66,7 & 80,0 \\
\hline No & 87,7 & 90,0 & 29,4 & 28,6 & 33,3 & 20,0 \\
\hline NC & & & 1,5 & 3,1 & & \\
\hline TOTAL ............................ & 100 & 100 & 100 & 100 & 100 & 100 \\
\hline
\end{tabular}

FUENTE: Elaboración propia.

${ }^{23}$ Hay que hacer notar en relación a estos datos que la pertenencia a comités ejecutivos nacionales es considerada como indicador de pertenencia a la élite política en todos los estudios sobre élites políticas. Por lo tanto, en el caso de ese 7,5 por 100 de diputados pertenecientes a los comités ejecutivos nacionales podemos señalar que pueden ser considerados miembros de la élite política por dos motivos, su condición de parlamentario y su condición de miembro del máximo órgano de poder del partido

${ }^{24}$ En relación a otros países, Pippa Norris y Joni Lovenduski destacan la gran importancia de los sindicatos como vía de reclutamiento de la élite política en el Partido Laborista británico, en P. Norris y J. Lovenduski, Political Recruitment, Cambridge University Press, Londres, 1995. 
Tenemos que tener en cuenta que un 27 por 100 de los diputados que pertenecen a sindicatos han ocupado cargos de responsabilidad en dichos sindicatos antes de ser diputados, lo que es un indicador interesante de la importancia, al menos en el pasado, de los sindicatos en la carrera política de las élites de los partidos de izquierda.

\section{TABLA 8}

Pertenencia a grupos de interés, a movimientos sociales y a organizaciones culturales según género (\%)

\begin{tabular}{|c|c|c|c|c|c|c|}
\hline & \multicolumn{2}{|c|}{ Grupos de interés } & \multicolumn{2}{|c|}{ Mov. sociales } & \multicolumn{2}{|c|}{ Org. culturales } \\
\hline & Hombre & Mujer & Hombre & Mujer & Hombre & Mujer \\
\hline Sí & 38,7 & 36,7 & 25,2 & 55,1 & 25,2 & 28,6 \\
\hline 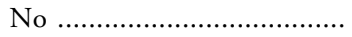 & 60,7 & 61,2 & 74,2 & 44,9 & 72,4 & 65,3 \\
\hline NC & 0,6 & 2,1 & 0,6 & & 2,5 & 6,1 \\
\hline TOTAL & 100 & 100 & 100 & 100 & 100 & 100 \\
\hline
\end{tabular}

FUENTE: Elaboración propia.

El análisis de los datos relativos a la pertenencia a grupos de interés y organizaciones culturales no revela diferencias de género. Tal como podemos ver en la tabla 8 , hombres y mujeres de la élite política pertenecen en porcentajes importantes a grupos de interés y a organizaciones culturales, sobre todo a los primeros: un 38,7 por 100 de los diputados y un 36,7 por 100 de las diputadas pertenecen a grupos de interés. La pertenencia a organizaciones culturales, si bien es también importante, es bastante menor que la correspondiente a grupos de interés: un 25,2 por 100 de los diputados y un 28,6 por 100 de las diputadas.

Ahora bien, sí se observan diferencias importantes entre diputados y diputadas cuando comparamos los niveles de pertenencia a movimientos sociales. En este caso, el nivel de pertenencia de las mujeres es mucho mayor (un 55,1 por 100, frente al 25,2 por 100 de los hombres) y se explica por la pertenencia a organizaciones feministas, que es muy elevada entre las diputadas de los partidos de izquierda y nula entre los diputados de partidos de izquierda y derecha.

\section{LOS PROCESOS DE RECLUTAMIENTO}

Existen notables semejanzas en las características de los hombres y mujeres que han llegado a posiciones de élite política. Ahora bien, persiste una impor- 
tante diferencia en el número de hombres y mujeres que llegan a esas posiciones. La explicación a esta desigual incorporación de hombres y mujeres se ha centrado tradicionalmente en la discriminación, en la discriminación ejercida por los partidos políticos sobre las mujeres. Dentro de los escasos o casi inexistentes trabajos españoles en torno a las élites políticas ${ }^{25}$ destaca el trabajo de María Antonia García de León, que en un análisis de las elecciones de 1989 se refiere a la doble discriminación impuesta por los partidos, la cuantitativa (el escaso número de mujeres candidatas al Parlamento) y la cualitativa (su pésima colocación en las listas electorales) ${ }^{26}$.

Ahora bien, los estudios más recientes sobre élites políticas, y en concreto la primera gran investigación comparada centrada en los procesos de reclutamiento político que ha analizado detenidamente la influencia del género, aportan nuevas tesis y, sobre todo, nuevos datos que ponen seriamente en cuestión la tesis de la discriminación ejercida por los partidos políticos ${ }^{27}$. Estos datos tienen enorme interés no sólo por el cuestionamiento que suponen de teorías ampliamente aceptadas, sino también porque constituyen las primeras evidencias empíricas consistentes sobre los procesos de reclutamiento políticos. Tenemos que tener en cuenta que la tesis de la discriminación ejercida por los partidos políticos estaba fundamentada básicamente en el análisis de las características de las listas electorales y, en menor grado, en las percepciones de las propias mujeres de las élites políticas.

Ahora bien, la investigación del equipo dirigido por Pippa Norris analiza directamente los procesos de reclutamiento. Para ese análisis, Pippa Norris parte de la constatación de que en todos los países estudiados, con excepción de Estados Unidos, que tiene un sistema peculiar de primarias, una de las funciones principales de los partidos políticos es la determinación de quién puede ser nombrado candidato entre el conjunto de todos los aspirantes. Por lo tanto, las reglas y procedimientos de los partidos determinan el proceso que todos los aspirantes deben pasar para ser nombrados candidatos. En este contexto, Pippa Norris y su equipo utilizan un modelo de oferta-demanda para analizar ese proceso.

En el terreno de la demanda se consideran las actitudes y exigencias de los seleccionadores que intervienen desde los partidos políticos en el reclutamiento de la élite política. En el contexto de la oferta se consideran el capital político y la motivación de los candidatos. El capital político significa los recursos que aportan los candidatos en el proceso, tales como recursos financieros,

${ }^{25}$ En relación al tardío interés de los estudios de género españoles en torno a las élites políticas, véase E. URIARTE, «Las mujeres en las élites políticas», dentro de E. URIARTE y A. ElizONDO, op. cit.

${ }_{26}^{26}$ M. A. García de LeÓn, Élites discriminadas, Anthropos, Barcelona, 1994.

27 Se trata de una investigación sobre reclutamiento político comparado en Australia, Canadá, Finlandia, Alemania, Japón, Holanda, Nueva Zelanda, Reino Unido y Estados Unidos. Los resultados principales de esta investigación, junto al análisis de numerosos datos sobre los miembros de la Unión Europea, se presentan en P. NORRIS, op. cit. 
conexiones políticas, experiencia de partido, flexibilidad profesional, formación o experiencia en las instituciones políticas. La motivación se refiere a las razones que impulsan a los candidatos a competir por entrar en las listas de candidatos, tales como la tradición familiar, la ambición política, el apoyo de una comunidad, etc. A partir de esta distinción, Pippa Norris establece que el sistema político configura el contexto general, el proceso de reclutamiento determina las etapas desde la aspiración a la nominación, mientras que las demandas de los seleccionadores y la oferta de los candidatos determinan el resultado final del proceso ${ }^{28}$.

A pesar de que Norris y su equipo partían de la hipótesis inicial de que encontrarían una importante discriminación por parte de los partidos políticos, los resultados finales fueron contrarios a los de la hipótesis inicial. Se hizo muy difícil establecer la evidencia de una discriminación directa o indirecta por parte de los partidos políticos contra las mujeres. Es más, el análisis reveló que las mujeres candidatas señalaban que habían recibido más apoyo que los hombres candidatos por parte de los diferentes niveles de poder de los partidos políticos. Y una de las conclusiones principales de la investigación estableció que los factores relacionados con la oferta, es decir, el capital político y la motivación, eran los factores que tenían una influencia principal en la configuración final de las candidaturas y, por lo tanto, también en el peso de la presencia femenina en esas candidaturas.

Si bien la investigación sobre la élite política española en la que están basadas estas páginas es una investigación sobre los parlamentarios y no sobre los procesos de selección de las candidaturas para el Parlamento, sí puede contribuir, sin embargo, a arrojar cierta luz desde el caso español al análisis de los factores que determinan la configuración por sexos de la élite política. Y lo puede hacer a través de dos elementos: 1) la propia caracterización de la élite política, y 2) las percepciones de los hombres y mujeres de la élite política en torno a las causas que determinan la menor presencia de mujeres en el poder político.

En relación a la caracterización, el análisis de los parlamentarios españoles mostraba que, al igual que en otros países, la élite política española se caracteriza en primer lugar por orígenes de clase medios-altos, por una alta formación y por una edad media bastante elevada. En el terreno de la formación encontramos un primer problema de oferta dado que es tan sólo en los últimos años cuando el acceso a la universidad de hombres y mujeres se equipara en España, y, por lo tanto, la formación de las mujeres de más de cuarenta años y, sobre todo, de más de cincuenta años es todavía inferior a la formación de los hombres

El segundo problema de oferta por parte de las mujeres se sitúa también en el terreno de la educación y en el de las profesiones. Se trata del contenido de la formación y del tipo de profesiones más adecuadas para el desarrollo de una

28 P. NORRIS, Passages to..., op. cit. 
carrera política. La formación más ligada a la política ha sido tradicionalmente la de Derecho, de la misma forma que la abogacía ha sido y continúa siendo todavía la profesión de origen más frecuente entre los políticos. Y, como es bien sabido, los estudios de Derecho y la profesión de abogado han sido hasta muy recientemente áreas de intensa presencia masculina pero muy débil participación femenina.

En tercer lugar, la afiliación femenina a los partidos políticos es todavía notablemente inferior a la masculina y, además, esta afiliación tan sólo ha aumentado recientemente, por lo que el número de mujeres con una larga trayectoria como afiliadas a partidos políticos es mucho menor que el de los hombres. Esta menor y más reciente afiliación constituye un obstáculo para consolidar posiciones de poder en el seno de los partidos y, como veíamos más arriba, la vinculación duradera a un partido político y el trabajo político en su seno son elementos de gran importancia para llegar a posiciones de élite.

En cuarto lugar, las posibilidades de acceso a la élite política están altamente relacionadas con una gran dedicación a las actividades de partido y a la actividad política en general. Y aquí nos encontramos con uno de los obstáculos más importantes que desde la oferta han dificultado la incorporación de las mujeres a las élites políticas. Se trata del papel familiar que han jugado tradicionalmente las mujeres y siguen jugando en gran medida en la actualidad. Este papel ha puesto la responsabilidad básica del cuidado de la casa y, sobre todo, de los hijos en manos de las mujeres, y ha supuesto un obstáculo de enorme importancia en sus posibilidades de acceso a las posiciones de poder político $^{29}$.

En este contexto se entiende que los porcentajes de solteras, separadas o divorciadas sean notablemente mayores entre las diputadas que entre los diputados (tabla 9). En este contexto se entiende también que las diputadas no tengan hijos en mayor medida que los diputados (un 32,7 por 100 de diputadas no tiene hijos, frente a un 13,5 por 100 de los diputados) y que el número de hijos entre las diputadas sea menor que entre los diputados (un 18,4 por 100 de diputadas tiene un solo hijo, frente a un 12,9 por 100 de los diputados, y un 24,5 por 100 de las diputadas tiene dos hijos, frente a un 36,2 por 100 de diputados). Este rasgo, sobre el que ya se ha llamado la atención respecto a anteriores legislaturas ${ }^{30}$, puede ser considerado, por lo tanto, como un factor explicativo más que debemos considerar dentro de los problemas de oferta.

Por otra parte, la importancia de la cuestión familiar como causa explicativa de los problemas de acceso de las mujeres a las élites políticas queda reforzada por el significativo porcentaje de mujeres que están de acuerdo con la idea

${ }^{29}$ Como señala Paul S. Herrnson en su análisis del proceso de reclutamiento en Estados Unidos, "Active campaigning demands greater time and flexibility than most people - but in particular, women - can afford. Women continue to assume primary parenting responsabilities in most families, a role that is difficult to combine with long hours of campaigning», en P. S. HERRNSON, "United States", dentro de P. NORRIS, op. cit.

${ }^{30}$ M. A. García de LeÓn, Élites discriminadas, Anthropos, Barcelona, 1995. 
de que la vida parlamentaria es poco práctica para las mujeres, un 30,6 por 100 de parlamentarias, frente al 15,9 por 100 de parlamentarios que tienen esta percepción. Las dificultades para combinar la vida familiar y las responsabilidades en relación a los hijos con los horarios y los hábitos de las élites políticas han sido destacadas por políticas de muchos países ${ }^{31}$, y la percepción de las políticas españolas vuelve a incidir sobre esta cuestión.

\section{TABLA 9}

Estado civil de los diputados (\%)

\begin{tabular}{|c|c|c|}
\hline & Hombre & Mujer \\
\hline Soltero & 8,0 & 16,3 \\
\hline 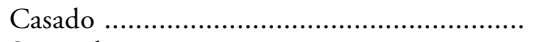 & 86,5 & 63,3 \\
\hline 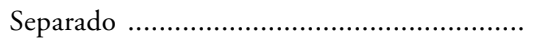 & 2,5 & 8,2 \\
\hline 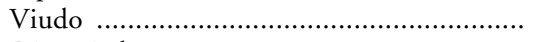 & 0,6 & \\
\hline 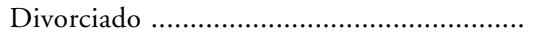 & 1,8 & 8,2 \\
\hline NC & 0,6 & 4,1 \\
\hline 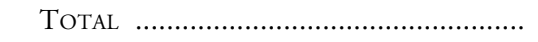 & 100 & 100 \\
\hline
\end{tabular}

FUENTE: Elaboración propia.

En definitiva, las mujeres se encuentran en una situación notablemente más desventajosa que los hombres en términos de capital político ya que disponen de menos tiempo y posibilidades de dedicación a la carrera política, su formación y experiencia profesional son menos adecuadas para la política y su afiliación y participación en partidos políticos es menor y más reciente.

¿Qué podemos señalar en relación a la motivación, es decir, al segundo componente de la oferta? Un análisis de las valoraciones realizadas por los diputados españoles en torno a las causas que explican la menor presencia de mujeres en las élites revela algunos datos muy significativos. Básicamente, nos encontramos con un importante número de respuestas, y, además, respuestas de las diputadas, que tienden a avalar la tesis de que en el terreno de la motivación es cierto que las mujeres también presentan algunos problemas que las debilitan desde el punto de vista de la oferta.

Así, más del 50 por 100 de diputados, pero también más del 50 por 100 de diputadas, del Congreso están de acuerdo con la idea de que las mujeres ponen a su familia por encima de su carrera política (tabla 10). Es decir, desde el punto de vista de la motivación, un primer obstáculo significativo para las

31 Véanse, L. Adler, Les femmes politiques, Seuil, París, 1993, y L. A. LisWOOD, Women World Leaders, Harper Collins, Londres, 1995. 
mujeres en el proceso de acceso a la élite política es la existencia de una tendencia importante a considerar que esa carrera política es secundaria respecto a la dedicación a la familia.

\section{TABLA 10}

Percepción de que las mujeres ponen a su familia por encima de su carrera política (\%)

\begin{tabular}{|c|c|c|}
\hline & Hombres & Mujeres \\
\hline Muy de acuerdo & 7,4 & 8,2 \\
\hline De acuerdo & 45,4 & 44,9 \\
\hline 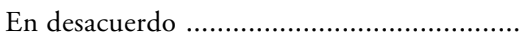 & 34,4 & 30,6 \\
\hline Muy en desacuerdo & 6,1 & 4,1 \\
\hline 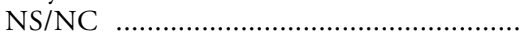 & 6,7 & 12,2 \\
\hline 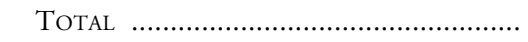 & 100 & 100 \\
\hline
\end{tabular}

FUENTE: Elaboración propia.

Además, un número importante de diputados, pero sobre todo de diputadas, nada menos que el 57,1 por 100 , está de acuerdo con la idea de que las mujeres compiten menos que los hombres (tabla 11). Es decir, las diputadas apuntan un segundo factor que, desde el punto de vista de la motivación, de las actitudes, complica la posición de las mujeres como aspirantes a acceder a posiciones de poder. Ahora bien, este dato puede sugerir que las mujeres son menos ambiciosas que los hombres, tesis que, por otra parte, ya se ha sostenido en algunos trabajos. Los datos que aporta, sin embargo, Pippa Norris en torno a la ambición expresada por hombres y mujeres candidatos al Parlamento Europeo muestran que, en contra de las hipótesis iniciales de esta autora, las mujeres se muestran claramente más ambiciosas que los hombres respecto a su carrera política. También hay que señalar que, como indica Pippa Norris, estos datos se refieren a candidatas y no a niveles inferiores de mujeres activistas o afiliadas a partidos políticos ${ }^{32}$.

Las diputadas conceden también cierta importancia, aunque menor, a la explicación de que las mujeres adolecen de autoestima. Un 6,1 por 100 de mujeres está muy de acuerdo con esta apreciación, y otro 18,4 por 100 está de acuerdo, es decir, un 24,5 por 100 de las diputadas otorga consistencia a esta explicación como uno de los factores explicativos de los problemas de las mujeres para acceder a la élite política. La percepción de que las mujeres no tienen suficiente autoestima se ha observado también en otros países. Así, Monique Leijenaar y Kees Niemöller apuntan en relación a Holanda que un

32 P. NORRIS, "Conclusions: Comparing...», op. cit. 
porcentaje significativo de mujeres candidatas está de acuerdo con la valoración de que las mujeres no tienen suficiente confianza en sí mismas; un 37 por 100 de las candidatas holandesas está de acuerdo con esa idea, frente a un 10 por 100 de los candidatos ${ }^{33}$.

\section{TABLA 11}

Percepción de que las mujeres compiten menos que los hombres (\%)

\begin{tabular}{|c|c|c|}
\hline & Hombres & Mujeres \\
\hline 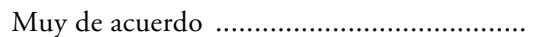 & 4,3 & 10,2 \\
\hline 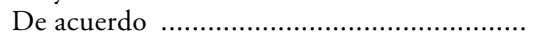 & 22,7 & 46,9 \\
\hline En desacuerdo & 47,7 & 26,5 \\
\hline Muy en desacuerdo ................................... & 20,9 & 12,2 \\
\hline NS/NC & 4,9 & 4,1 \\
\hline 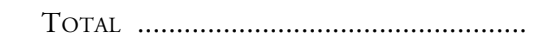 & 100 & 100 \\
\hline
\end{tabular}

FUENTE: Elaboración propia.

A ambas valoraciones se añaden, por último, otros porcentajes importantes de diputados y diputadas, un 33,1 y un 24,4 por 100 , respectivamente, que están de acuerdo con la percepción de que las mujeres están menos interesadas en política y con la idea de que ese menor interés contribuye también a explicar sus mayores dificultades para llegar a las élites políticas. Tal como hemos visto en páginas anteriores, esta percepción está avalada con respecto al conjunto de la población por numerosos estudios que constatan la importante diferencia de interés respecto a la política entre hombres y mujeres, una diferencia que, si bien se reduce considerablemente en los hombres y mujeres con formación superior, aún se mantiene también en esos niveles educativos ${ }^{34}$.

La tesis, por lo tanto, de que los problemas principales que explican la todavía escasa presencia de las mujeres en la élite política deben buscarse en el terreno de la oferta encuentra numerosos datos de apoyo en el análisis de la élite política española. La percepción sobre los obstáculos a los que se enfrentan las mujeres en la política puede ser resumida con la valoración que hacía la política danesa Lone Dybkjaer. Ésta señalaba que los hombres no constituyen el principal obstáculo al que se enfrentan las mujeres, sino que los obstáculos

33 M. LeijenaAR y K. Niemöller, op. cit.

${ }^{34}$ Recordemos que, incluso en hombres y mujeres de niveles altos de formación, la diferencia entre hombres y mujeres muy y bastante interesados en política es de 14 puntos todavía en 1989 (un 60 por 100 de los hombres, frente a un 46 por 100 de las mujeres), en M. L. MORÁN y J. Benedicto, La cultura politica de los españoles, CIS, Madrid, 1995. 
son otros dos, los hijos y la falta de ambición: "La primera (barrera) hace que las mujeres estén divididas entre sus hijos e hijas y la vida profesional. La principal exigencia de los hijos e hijas es la presencia de un padre o una madre; igualmente la principal exigencia de un jefe, o del que pretende ser jefe, es también la presencia. En esta situación de división, las mujeres abandonan (...) Convendremos que existe un segundo obstáculo, las mismas mujeres, a saber: no tienen las mismas exigencias que los hombres en materia de trayectoria profesional y no conocen tan bien como los hombres las profesiones que ofrecen más posibilidades de progreso" ${ }^{35}$.

¿Debemos, por lo tanto, suponer que la discriminación ejercida por los partidos políticos tiene escasa importancia? Si bien los datos aportados por el equipo de Pippa Norris sugieren que no se ha podido constatar esa discriminación, lo cierto es que las políticas españolas perciben, y de forma muy importante, que esa discriminación sí se produce. Como podemos ver en la tabla 12, nada menos que un 83,6 por 100 de las diputadas españolas cree que los partidos no dan suficientes oportunidades a las mujeres. A ellas debemos sumar, además, el significativo 44,2 por 100 de diputados que está de acuerdo con dicha valoración. Los políticos españoles, por lo tanto, pero muy especialmente las políticas, continúan percibiendo un importante efecto de discriminación desde los propios partidos políticos.

Este dato, además, encuentra paralelos en experiencias políticas de otros países. Así, en el estudio de Monique Leijenaar y Kees Niemöller sobre el proceso de reclutamiento político en Holanda se constata que un 40 por 100 de las mujeres candidatas y un 26 por 100 de los hombres candidatos están de acuerdo con la idea de que los partidos no dan suficientes oportunidades a las mujeres ${ }^{36}$. Numerosos testimonios de políticas de diversos países, por otra parte, destacan la percepción de que su condición de mujeres les ha supuesto dificultades específicas y añadidas en sus carreras políticas. Laure Adler recoge numerosas reflexiones de políticas francesas que destacan esta percepción, y Laura A. Liswood también encuentra abundantes críticas a la discriminación sufrida como mujeres en sus entrevistas con mujeres líderes políticas de todo el mundo ${ }^{37}$.

La importancia de la percepción de discriminación por parte de las propias mujeres de las élites políticas en España y en otros países nos lleva a pensar que es preciso seguir profundizando en el modelo de la oferta y la demanda, que es conveniente explorar la vertiente de la oferta, muy especialmente en países como España en los que hasta ahora no se ha considerado, pero que no hay que olvidar el análisis de la demanda.

35 L. DybKJaer, discurso pronunciado dentro de la Conferencia Mujeres en el Poder, en INSTITUTO DE LA Mujer, Informe final conferencias de la Cumbre de Atenas, Madrid, 1993.

${ }^{36}$ M. LEIJENAAR y K. NiEMÖller, op. cit.

37 L. ADLER, op. cit., y L. A. LISWOOD, op. cit. 
TABLA 12

Percepción de que los partidos no dan suficientes oportunidades a las mujeres (\%)

\begin{tabular}{|c|c|c|}
\hline & Hombres & Mujeres \\
\hline Muy de acuerdo . ......................................... & 5,5 & 26,5 \\
\hline 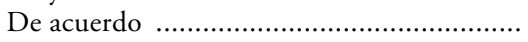 & 38,7 & 57,1 \\
\hline En desacuerdo & 38,7 & 12,2 \\
\hline Muy en desacuerdo ................................... & 10,4 & \\
\hline 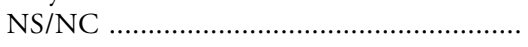 & 6,7 & 4,1 \\
\hline 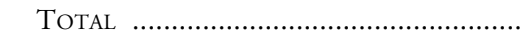 & 100 & 100 \\
\hline
\end{tabular}

FUENTE: Elaboración propia.

\section{¿DIFERENCIAS DE LIDERAZGO?}

Una cuestión de gran interés en el análisis de las élites políticas es la relativa a las formas de ejercer el liderazgo político por parte de hombres y mujeres. Algunos análisis sobre las élites políticas han planteado la doble interrogante de si, por una parte, las mujeres mandan de forma diferente y de si, por otra parte, diseñan y apoyan políticas diferentes de las de los hombres. Veamos cuál es la percepción de los diputados españoles en torno a la primera de estas interrogantes.

Dentro de las tesis que encuentran diferencias en el estilo de liderazgo de hombres y mujeres, Judy Rosener ha señalado que existe un estilo de liderazgo femenino diferente del masculino que se caracteriza por ser más interactivo, por estimular la participación, por ser menos agresivo y porque tiende más a compartir ${ }^{38}$. Pero no todos los investigadores han podido constatar estas diferencias. Michael Genovese no ha encontrado evidencias claras de esas diferencias en su estudio de varias líderes políticas del mundo y ha señalado que, más que estilos diferentes de liderazgo, lo que existen son situaciones diferentes que requieren liderazgos diferentes y que el líder con éxito es aquel que reconoce y se adapta a esas situaciones ${ }^{39}$.

Ahora bien, la percepción de la gran mayoría de mujeres situadas en las élites políticas destaca las diferencias. Los testimonios de las numerosas mujeres políticas entrevistadas por Laure Adler y Laura Liswood destacan la existencia de diferencias en su percepción de la forma en que hombres y mujeres de la política ejercen sus responsabilidades de $\operatorname{poder}^{40}$. En las apreciaciones de los

${ }^{38}$ J. B. Rosener, "Ways Women Lead», Harvard Business Review, vol. 68, núm. 6, noviembre-diciembre 1990.

39 M. GenOveSE, Women as National Leaders, Sage, Newbury Park, 1993.

${ }^{40}$ L. AdLer, op. cit., y L. A. LisWoOd, op. cit. Para un análisis más detallado de los testimonios recogidos en estos dos libros, véase E. URIARTE, "Las mujeres en las élites políticas», op. cit. 
diputados españoles, especialmente de las diputadas, encontramos también un notable apoyo a la tesis de la existencia de un estilo de liderazgo diferenciado de hombres y mujeres. Tal como podemos ver en la tabla 13, son sobre todo las propias mujeres las que resaltan esas diferencias. Mientras la gran mayoría de los diputados está de acuerdo con la idea de que no existen diferencias, nada menos que un 46,9 por 100 de las diputadas muestra su desacuerdo con la idea de la igualdad en los estilos de liderazgo. Y, como veremos en las siguientes valoraciones, también los hombres inciden en la percepción de estas diferencias en su opinión sobre algunas de las reflexiones que se han realizado sobre los estilos de liderazgo masculinos y femeninos, a pesar de su afirmación inicial de que no existen diferencias entre hombres y mujeres.

\section{TABLA 13}

Grado de acuerdo según género con la frase

"No existen diferencias entre hombres y mujeres en el ejercicio de las tareas políticas» (\%)

\begin{tabular}{|c|c|c|}
\hline & Hombres & Mujeres \\
\hline Muy de acuerdo . ........................................... & 39,9 & 12,2 \\
\hline De acuerdo ................................................ & 45,4 & 34,7 \\
\hline En desacuerdo ........................................... & 12,9 & 40,8 \\
\hline Muy en desacuerdo .................................... & & 6,1 \\
\hline 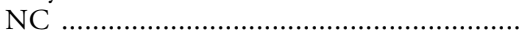 & 1,8 & 6,1 \\
\hline 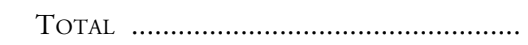 & 100 & 100 \\
\hline
\end{tabular}

FUENTE: Elaboración propia.

¿Cuáles son esas diferencias que sobre todo perciben las propias diputadas pero también los diputados? En términos generales, podemos decir que las diputadas españolas, y en menor medida los diputados, comparten las conclusiones que la investigadora norteamericana Judy Rosener presentaba en su investigación sobre directivas de empresa norteamericanas y sus estilos de liderazgo, es decir, los diputados españoles comparten la idea de que el estilo de liderazgo femenino es más interactivo, estimula más la participación, es menos agresivo y tiende más a compartir.

Como podemos ver en la tabla 14, un 23,9 por 100 de los diputados está de acuerdo con la opinión de que las mujeres son más dialogantes en el ejercicio del poder, pero, sobre todo, más del 80 por 100 de las diputadas coincide con esta idea. La apreciación sobre el estilo más dialogante de las mujeres se complementa con la idea de que las mujeres son menos autoritarias y, además, integran más a sus subordinados y estimulan mejor su trabajo. 


\section{TABLA 14}

Grado de acuerdo según género con la frase "Las mujeres utilizan más el diálogo para solucionar los problemas» (\%)

\begin{tabular}{|c|c|c|}
\hline & Hombres & Mujeres \\
\hline 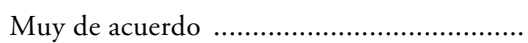 & 3,7 & 30,6 \\
\hline 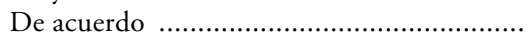 & 20,2 & 53,1 \\
\hline En desacuerdo & 65,0 & 12,2 \\
\hline 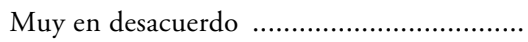 & 4,9 & \\
\hline $\mathrm{NC}$ & 6,1 & 4,1 \\
\hline TOTAL & 100 & 100 \\
\hline
\end{tabular}

FUENTE: Elaboración propia.

\section{TABLA 15}

Grado de acuerdo según género con la frase

"Las mujeres son menos autoritarias» (\%)

\begin{tabular}{|c|c|c|}
\hline & Hombres & Mujeres \\
\hline Muy de acuerdo & 1,8 & 12,2 \\
\hline De acuerdo & 14,7 & 51,0 \\
\hline 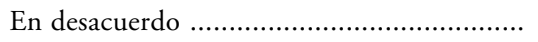 & 70,6 & 30,6 \\
\hline Muy en desacuerdo & 6,7 & 2,0 \\
\hline NC & 6,1 & 4,1 \\
\hline 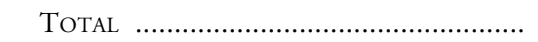 & 100 & 100 \\
\hline
\end{tabular}

FUENTE: Elaboración propia.

Una vez más, la percepción sobre el menor grado de autoritarismo de las mujeres es mucho más pronunciada entre las diputadas que entre los diputados. Observamos en la tabla 15 que un 63,2 por 100 de las diputadas está de acuerdo con la idea de que las mujeres son menos autoritarias, frente a tan sólo un 16,5 por 100 de los diputados.

Las diputadas también están mayoritariamente de acuerdo con la apreciación de que las mujeres integran más a sus subordinados y estimulan mejor su trabajo, nada menos que un 85,7 por 100 (tabla 16), y, aunque en este caso el grado de acuerdo de los diputados es algo mayor (26,4 por 100), sigue observándose una importante diferencia en la lectura que realizan sobre los estilos de liderazgo femeninos y masculinos. 


\section{TABLA 16}

Grado de acuerdo según género con la frase "Las mujeres integran más a sus subordinados y estimulan mejor su trabajo» (\%)

\begin{tabular}{|c|c|c|}
\hline & Hombres & Mujeres \\
\hline Muy de acuerdo . ......................................... & 1,2 & 40,8 \\
\hline 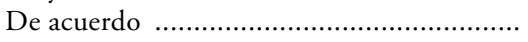 & 25,2 & 44,9 \\
\hline 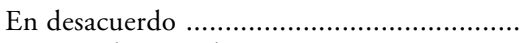 & 58,3 & 8,2 \\
\hline 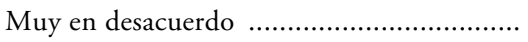 & 6,7 & \\
\hline NC & 8,6 & 6,1 \\
\hline TOTAL & 100 & 100 \\
\hline
\end{tabular}

FUENTE: Elaboración propia.

\section{TABLA 17}

Grado de acuerdo según género con la frase "Las mujeres son menos eficaces» (\%)

\begin{tabular}{|c|c|c|}
\hline & Hombres & Mujeres \\
\hline 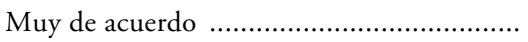 & & 2,0 \\
\hline De acuerdo & & 2,0 \\
\hline 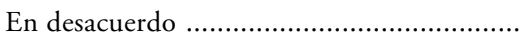 & 62,0 & 32,7 \\
\hline Muy en desacuerdo & 31,9 & 59,2 \\
\hline NC & 6,1 & 4,1 \\
\hline TOTAL & 100 & 100 \\
\hline
\end{tabular}

FUENTE: Elaboración propia.

Diputados y diputadas sí coinciden en sus opiniones negativas en torno a las ideas de que las mujeres son menos eficaces y de que tienen menos capacidad de imponer sus opiniones. El desacuerdo es generalizado en torno a la idea de que las mujeres son menos eficaces (tabla 17). Ahora bien, llama la atención no sólo el pequeño porcentaje de diputadas (4 por 100) que sí piensa que las mujeres son menos eficaces en el ejercicio de las responsabilidades políticas, sino sobre todo la mayor contundencia en el rechazo que las mujeres manifiestan hacia esta apreciación (un 59,2 por 100 de diputadas muy en desacuerdo, frente a un 31,9 por 100 de diputados).

Existe, por último, una opinión en la que la apreciación de diputados y diputadas es muy semejante. Se trata de su opinión contraria a la idea de que las mujeres tienen menos capacidad de imponer sus opiniones. El grado de desacuerdo con esta idea vuelve a ser más contundente en las diputadas, ya que 
un 38,9 por 100 señala que está muy en desacuerdo, frente a un 27,6 por 100 de hombres que mantiene la misma opinión. Esta diferencia queda matizada, sin embargo, por el significativo porcentaje de diputadas que está muy de acuerdo o de acuerdo con la apreciación de que las mujeres tienen menos capacidad de imponer sus opiniones: un 12,3 por 100 .

En definitiva, los diputados españoles piensan que sí existen algunas diferencias entre hombres y mujeres en sus estilos de liderazgo. La percepción entre las diputadas sobre estas diferencias es, además, muy acentuada. ¿Qué diferencias? Básicamente, que las políticas son más dialogantes, menos autoritarias y que tienen más capacidad para integrar y estimular a sus subordinados. $\mathrm{Ni}$ diputados ni diputadas piensan que se pueden extender estas diferencias al ámbito de la eficacia y de la capacidad de imponer sus opiniones, pero sí expresan algunas dudas sobre la cuestión.

\section{ABSTRACT}

This paper analyses gender differences in the Spanish political elite by drawing on data obtained from the research conducted by the authors in 1997 on men and women members of parliament in the present legislature. The paper begins with an introductory analysis of the factors which account for the large percentage, in comparative terms, of women who have carved out a presence for themselves in Spain's political elite and the factors which explain the prevailing differences between the number of men and women in politics. In this paper, the authors try to answer three basic questions: 1) Do differences exist between the men and women in Spain's political elite? 2) What are the reasons for the narrower presence of women in positions of political authority?, and 3) Can we talk about differences in the way men and women exercise their leadership? 